\title{
Difference in the prevalence of hypertension and its risk factors depending on area-level deprivation in Japan
}

Tasuku Okui ${ }^{*}$ (D) and Jinsang Park ${ }^{2}$

\begin{abstract}
Objectives: Area-level deprivation is an important factor related to mortality or health behaviors; however, a study investigating differences in hypertension prevalence depending on area-level deprivation has not been conducted in Japan. We investigated differences in the prevalence of hypertension and its risk factors, i.e. obesity, smoking, alcohol consumption, and heavy alcohol drinking depending on area-level deprivation using nationwide health checkups data in 2018.

Results: Area-level deprivation was derived from census data. An analysis of the data by secondary medical areas revealed that the age-standardized proportions of individuals whose systolic blood pressure was $\geq 140 \mathrm{mmHg}$, those whose diastolic blood pressure was $\geq 90 \mathrm{mmHg}$, those whose body mass index was $\geq 25$ or $30 \mathrm{~kg} / \mathrm{m}^{2}$, smokers, and heavy alcohol drinkers showed an increasing trend with an increase in the deprivation level. The relative index of inequality, which can be interpreted as the ratio of the age-standardized proportion for the most deprived area compared with that for the least deprived area, was significantly greater than 1 for all proportions, except for the proportion of drinkers in women. Overall, there was a disparity in the prevalence of hypertension and its risk factors depending on area-level deprivation.
\end{abstract}

Keywords: Japan, Hypertension, Obesity, Smoking, Alcohol drinking

\section{Introduction}

Hypertension is a major risk factor for cardiovascular diseases and one of the leading causes with a significant effect on mortality in Japan [1]. Mean systolic and diastolic blood pressures are shown to have decreased over recent years in Japan [2]. However, the current prevalence of hypertension is approximately $30 \%$ and $20 \%$, respectively, for men and women aged 20 or more years in Japan [2]. Preventing occurrence of hypertension is still an important public health concern in Japan.

*Correspondence: task10300@gmail.com

${ }^{1}$ Medical Information Center, Kyushu University Hospital, Maidashi3-1-1

Higashi-ku, Fukuoka, Fukuoka 812-8582, Japan

Full list of author information is available at the end of the article
Several studies have shown that there are regional differences in the prevalence of hypertension in Japan [3, 4]. One such study revealed that the number of steps taken by an individual was significantly associated with prevalence [3]. However, a study investigating regional differences in hypertension prevalence depending on area-level deprivation has not been conducted in Japan. In other countries, area-level deprivation or socioeconomic position is shown to be significantly associated with regional hypertension prevalence $[5,6]$. In Japan, stroke incidence or all-cause mortality is shown to be affected by area-level deprivation [7, 8]. Some behaviors, such as unhealthy dietary habits, were also shown to be associated with area-level deprivation in epidemiological studies $[9,10]$. Therefore, it is important to verify the disparity in hypertension prevalence. In addition, factors 
such as obesity, smoking, and alcohol drinking are known to be risk factors for hypertension in Japan [11-16], and these risk factors for hypertension might also vary depending on area-level deprivation. However, an association between these factors and area-level deprivation has not been investigated using nationwide government statistics in Japan. If an association between area-level deprivation and prevalence of hypertension and its risk factors exists, we might be able to conduct administrative preventive measures focusing on those areas.

Here, we investigated differences in proportions of hypertension and its risk factors depending on area-level deprivation using specific health checkup data in Japan.

\section{Main Text Methods}

The Ministry of Health, Labor, and Welfare in Japan began performing specific health checkups and providing specific health guidance from 2008 [17]. Insured persons and their dependents aged 40-74 years are encouraged to receive a medical checkup concerning lifestyle-related diseases every year $[17,18]$. If a person has a high possibility of developing a lifestyle-related disease, they receive specific health guidance. We used data on results of the checkups by five-year age groups, sex, and secondary medical areas in 2018 [19]. Specifically, we used data on systolic blood pressure (BP), diastolic BP, body mass index (BMI), smoking status, alcohol drinking status, and amount of alcohol drinking for the analysis. BP and BMI are measured in the checkups, while smoking and alcohol drinking status are self-reported by questionnaires. The secondary medical area is a unit of regions which is smaller than a prefecture, but is larger than a municipality [20]. In addition, map data of Japan were obtained from a government website [21]. We used the specific health checkup data conducted by the government, and sample size estimation was not conducted for this study.

$\mathrm{BMI} \geq 25 \mathrm{~kg} / \mathrm{m}^{2}$ was categorized as obesity, and systolic $\mathrm{BP} \geq 140$ and diastolic $\mathrm{BP} \geq 90$ were each categorized as hypertension [22]. According to the criteria proposed by the World Health Organization, BMI $\geq 30 \mathrm{~kg} / \mathrm{m}^{2}$ was categorized as obesity [23], whereas BMI $\geq 25 \mathrm{~kg} / \mathrm{m}^{2}$ has been proposed as the criterion for obesity in Asian and Japanese people [24, 25]. We also showed the results of $\mathrm{BMI} \geq 30 \mathrm{~kg} / \mathrm{m}^{2}$ in addition to BMI $\geq 25 \mathrm{~kg} / \mathrm{m}^{2}$ for reference. Regarding alcohol drinking status, a participant is asked in a questionnaire the frequency of drinking alcoholic beverages. The choices are "every day," "sometimes," and "not drink." We categorized "everyday" and "sometimes" as drinkers. In another questionnaire, a participant is asked about alcohol drinking amount per drinking day based on gou (unit of sake). Annotation of the questionnaire explains 1 gou ( $180 \mathrm{ml}$ of sake) is approximately equivalent to: $500 \mathrm{ml}$ of beer, $110 \mathrm{ml}$ of syochu, $60 \mathrm{ml}$ of whiskey, or $240 \mathrm{ml}$ of wine. The answer choices are "Under 1 gou", "1-2 gou", "2-3 gou", and " 3 gou or more". We defined 2 gou or more for men and 1 gou or more for women per drinking day as heavy drinkers because these alcohol consumptions are shown to be related to hypertension incidence in Japan [15].

Area-level deprivation was calculated based on a method proposed in a previous study [8], which has been used for several studies $[7,9]$. The area-level deprivation was derived based on the following equation using characteristics available in the Census data, and a detailed explanation has been provided in a previous study [8].

$$
\begin{aligned}
\text { Area level deprivation }= & 2.99 \times \text { proportion of old couple households } \\
& +7.57 \times \text { proportion of old single households } \\
& +17.4 \times \text { proportion of fatherless households } \\
& +2.22 \times \text { proportion of rent houses } \\
& +4.03 \times \text { proportion of sales and service workers } \\
& +6.05 \times \text { proportion of agricultural workers } \\
& +5.38 \times \text { proportion of blue-collar workers } \\
& +18.3 \times \text { unemployment rate }
\end{aligned}
$$

The Census data in 2015 was used in this study because the most recent data currently available was that of 2015 $[26,27]$.

We classified the secondary medical areas by area-level deprivation into 5 quintiles, and showed them in a map of Japan. In addition, we calculated age-standardized proportions of each of the outcomes by sex and the quintiles, by using age-group specific number of participants in all of Japan as a standard population. Moreover, we calculated slope index of inequality (SII) and relative index of inequality (RII) for age-standardized proportions of each of the outcomes. SII and RII are often used for quantifying degree of health disparities [28-30]. 95\% confidence interval (CI) for RII was calculated based on bootstrap method. All statistical analyses were conducted using R3.6.3 (https://www.R-project.org/).

\section{Results}

Additional file 1: Table S1 shows basic characteristics of variables used in this study for the 335 secondary medical areas.

Figure 1 shows a map of area-level deprivation in Japan. The most deprived areas tended to be observed in Hokkaido and Okinawa; whereas, the central parts are less likely to be deprived.

Additional file 1: Table S2 shows the number of participants for each type of measurement by deprivation level. The number of participants tends to be smaller in more deprived areas because populations tend to be smaller in deprived areas. 


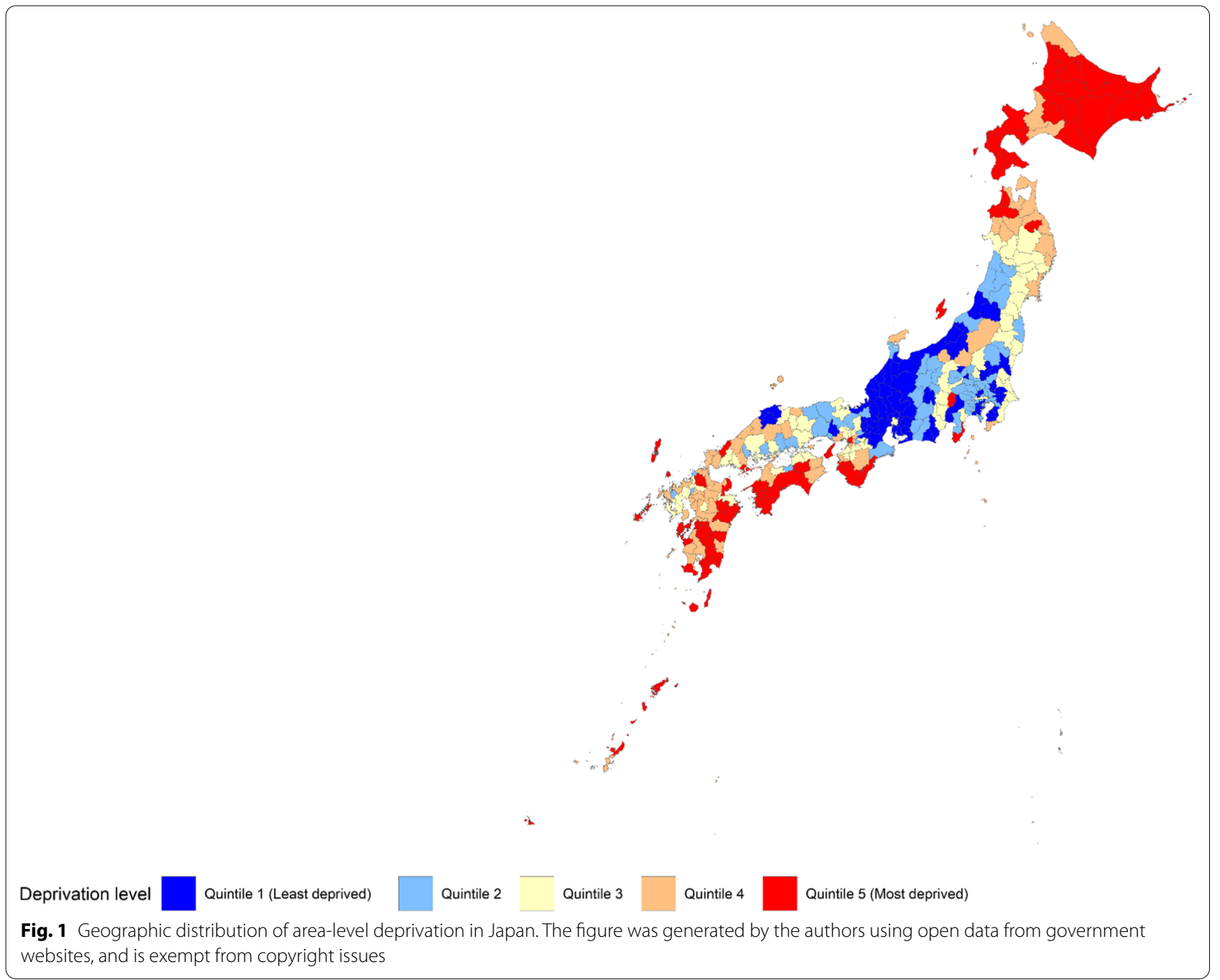

Additional file 1: Table S3 shows sex and age-group specific proportion of each of the outcomes in all of Japan. The proportions largely varied depending on age groups, suggesting an analysis adjusting for age is important.

Table 1 shows age-standardized proportions of the outcomes by the area-level deprivation by sex. The proportion showed an increasing trend as the deprivation level increased in most of the outcomes.

Table 2 shows the SII and RII for the outcomes. A significant disparity dependent on the area-level deprivation was observed regardless of sex and the outcomes, except for the proportion of drinkers in women.

\section{Discussion}

We showed that prevalence of hypertension and its risk factors was different depending on area-level deprivation. Here we discuss possible reasons for the results and implications.
An association between regional deprivation level and obesity prevalence was shown for the first time in Japan; whereas, it was known that regional differences in average income level, educational level, or unemployment rate was related to obesity prevalence [31,32]. In other developed countries, an association between area-level deprivation and obesity prevalence has been shown [3335]. The lack of healthy food or the lack of recreational infrastructure has been pointed as possible causes [33, 36, 37]. An association between low socioeconomic status or area-level deprivation and unhealthy dietary habits are also shown in Japan $[10,38,39]$. Therefore, the unhealthy dietary habits are possible causes of the associations. In contrast, globally, obesity is not necessarily negatively associated with low socioeconomic status. In low- and 
Table 1 Age-standardized proportions of the outcomes by the area-level deprivation by sex

\begin{tabular}{|c|c|c|c|c|c|}
\hline \multirow[t]{2}{*}{ Variable } & \multicolumn{5}{|c|}{ Area-level deprivation } \\
\hline & $\begin{array}{l}\text { Quintile } 1 \text { (Least } \\
\text { deprived areas) }\end{array}$ & Quintile 2 & Quintile 3 & Quintile 4 & $\begin{array}{l}\text { Quintile } 5 \text { (Most } \\
\text { deprived areas) }\end{array}$ \\
\hline \multicolumn{6}{|l|}{ Men } \\
\hline Proportion of persons whose systolic $B P \geq 140$ ( $\mathrm{mmHg})$ & 18.3 & 18.9 & 19.4 & 20.2 & 21.4 \\
\hline Proportion of persons whose diastolic $\mathrm{BP} \geq 90(\mathrm{mmHg})$ & 15.9 & 16.7 & 16.7 & 16.9 & 17.4 \\
\hline Proportion of persons whose $\mathrm{BMI} \geq 25\left(\mathrm{~kg} / \mathrm{m}^{2}\right)$ & 33.6 & 34.7 & 35.1 & 36.7 & 37.6 \\
\hline Proportion of persons whose $\mathrm{BMI} \geq 30\left(\mathrm{~kg} / \mathrm{m}^{2}\right)$ & 5.6 & 5.9 & 5.9 & 6.4 & 6.7 \\
\hline Proportion of smokers & 32.5 & 33.1 & 33.8 & 35.2 & 36.5 \\
\hline Proportion of drinkers & 69.3 & 69.8 & 69.8 & 70.8 & 70.7 \\
\hline Proportion of heavy alcohol drinkers & 23.6 & 24.4 & 24.3 & 24.4 & 26.2 \\
\hline \multicolumn{6}{|l|}{ Women } \\
\hline Proportion of persons whose systolic BP $\geq 140(\mathrm{mmHg})$ & 14.1 & 14.4 & 14.6 & 14.8 & 15.9 \\
\hline Proportion of persons whose diastolic $\mathrm{BP} \geq 90(\mathrm{mmHg})$ & 7.2 & 7.7 & 7.4 & 7.4 & 7.7 \\
\hline Proportion of persons whose $\mathrm{BMI} \geq 25\left(\mathrm{~kg} / \mathrm{m}^{2}\right)$ & 19.2 & 20.2 & 20.5 & 21.7 & 23.1 \\
\hline Proportion of persons whose $\mathrm{BMI} \geq 30\left(\mathrm{~kg} / \mathrm{m}^{2}\right)$ & 3.8 & 4.1 & 4.2 & 4.5 & 5.0 \\
\hline Proportion of smokers & 8.7 & 9.9 & 9.7 & 10.4 & 13.0 \\
\hline Proportion of drinkers & 40.9 & 42.7 & 41.6 & 42.0 & 41.8 \\
\hline Proportion of heavy alcohol drinker & 24.3 & 24.7 & 25.2 & 25.9 & 27.8 \\
\hline
\end{tabular}

$B M I$ body mass index, $B P$ blood pressure

Table 2 Degree of the disparity in the outcomes depending on area-level deprivation

\begin{tabular}{|c|c|c|c|c|}
\hline \multirow[t]{2}{*}{ Variable } & \multicolumn{2}{|l|}{ Men } & \multicolumn{2}{|l|}{ Women } \\
\hline & SII $(95 \% \mathrm{Cl})^{\mathrm{a}}$ & RII $(95 \% \mathrm{Cl})^{\mathrm{b}}$ & SII $(95 \% \mathrm{Cl})^{\mathrm{a}}$ & RII $(95 \% \mathrm{Cl})^{\mathrm{b}}$ \\
\hline Proportion of persons whose systolic BP $\geq 140(\mathrm{mmHg})$ & $3.36(2.46,4.26)$ & $1.18(1.13,1.23)$ & $2.04(1.29,2.78)$ & $1.14(1.09,1.20)$ \\
\hline Proportion of persons whose diastolic $\mathrm{BP} \geq 90(\mathrm{mmHg})$ & $1.66(0.88,2.44)$ & $1.10(1.05,1.15)$ & $0.45(0.03,0.87)$ & $1.06(1.00,1.13)$ \\
\hline Proportion of persons whose $\mathrm{BMI} \geq 25\left(\mathrm{~kg} / \mathrm{m}^{2}\right)$ & $6.01(4.95,7.08)$ & $1.19(1.15,1.22)$ & $5.26(4.22,6.29)$ & $1.28(1.22,1.34)$ \\
\hline Proportion of persons whose $\mathrm{BMI} \geq 30\left(\mathrm{~kg} / \mathrm{m}^{2}\right)$ & $1.52(1.15,1.90)$ & $1.29(1.21,1.38)$ & $1.37(1.05,1.70)$ & $1.37(1.28,1.48)$ \\
\hline Proportion of smokers & $4.52(3.45,5.60)$ & $1.14(1.10,1.17)$ & $3.50(2.60,4.40)$ & $1.44(1.30,1.58)$ \\
\hline Proportion of drinkers & $2.81(1.59,4.02)$ & $1.04(1.02,1.06)$ & $0.70(-0.98,2.38)$ & $1.02(0.97,1.06)$ \\
\hline Proportion of heavy alcohol drinkers & $3.20(1.74,4.67)$ & $1.15(1.08,1.23)$ & $4.37(2.50,6.23)$ & $1.20(1.11,1.30)$ \\
\hline
\end{tabular}

Cl confidence interval, SII Slope index of inequality, RII Relative index of inequality, BMI body mass index, BP blood pressure

${ }^{a}$ SII can be interpreted as the difference of age-standardized proportion between the most deprived area and that for the least deprived area

${ }^{\mathrm{b}} \mathrm{RII}$ can be interpreted as the ratio of age-standardized proportion for the most deprived area compared with that for the least deprived area

middle-income countries, the prevalence of overweight or obesity tended to increase with wealth [40].

Smoking is another major risk factor for hypertension $[11,41]$ and a risk factor for cardiovascular diseases in Japan [42]. An association between smoking and low socioeconomic status has been shown in many studies $[43,44]$. Possible reasons for an association between low socioeconomic status and smoking are that persons with low socioeconomic status are less frequently exposed to public health campaigns or that opportunities for smoking may still be greater in low socioeconomic status groups [45]. Additionally, it is considered that there are regional differences in policies for no smoking in restaurants or workplaces, and regional differences might also exist for a number of clinics conducting treatment for smoking cessation. Those factors may vary depending on area-level deprivation.

Proportion of heavy alcohol drinking was related to area-level deprivation both in men and women, whereas, prevalence of alcohol drinkers was not associated with it in women. Alcohol drinking is known to be positively related to high educational level; however, problematic or heavy alcohol drinking is related to lower educational level in Japan [46, 47]. Therefore, it is not surprising that proportion of alcohol drinkers did not differ depending on area-level deprivation. A possible reason for an 
association between heavy alcohol drinking and individual socioeconomic status in Japan can be due to education increasing understanding of the negative effects of heavy alcohol drinking [47]. Also, an association between heavy alcohol drinking and area-level deprivation was shown in studies in other countries [48, 49], and an increased alcohol outlet density in deprived areas was pointed out as a factor [48]. In contrast, according to a study carried out in the United States, people in the least deprived neighborhoods were most likely to be the heaviest alcohol drinkers [50], and a survey carried out in the U.K. revealed that people in the most deprived neighborhoods were less likely to report excess consumption in comparison with those in the least deprived ones [51]. Therefore, the relationship between alcohol drinking and neighborhood deprivation varies from one country to another.

Other factors, such as dietary habits and treatment rate are also considered to be related to the regional disparity in hypertension prevalence. Participation rate of health checkups is affected by income level in Japan [38]. Therefore, it is possible that detection of hypertension occurs late for persons with low socioeconomic status. In addition, low income level is also known to be associated with decreased access to outpatient care [52], and treatment status of hypertension might be also affected by socioeconomic status. Salt intake is another major factor related to the trend of hypertension prevalence in Japan [53], with salt intake also being affected by socioeconomic status $[12,54]$.

There are people who are not participating in the specific health checkups, such as non-insured persons, and detecting and treating hypertension patients, including the non-participants, early in the deprived areas is important. In addition, it is important to assess differences in environments affecting health behaviors depending on area-level deprivation, such as number of alcohol outlets, smoking areas, clinics conducting medical care for smoking cessation, and public infrastructure for physical activity. Moreover, there are some common fundamental causes for the disparity in those risk factors, such as low educational level and low income. It is considered that people in deprived areas are mutually affected by unfavorable health behaviors of people in those areas. Therefore, massive health education and health checkups targeting all of the citizens from childhood is considered to be particularly important in the deprived areas.

\section{Limitations}

Firstly, participation in the specific health checkups is not mandatory, and participation rate is a little higher than 50\% [17]. Therefore, differences in participation rates among regions might have affected the results of this study. Secondly, smoking and alcohol drinking status is based on self-reported questionnaires, which may have led to certain inaccurate responses. Thirdly, we could obtain data on average alcohol consumption per drinking day and frequency of alcohol drinking. However, data on alcohol consumption per day could not be obtained, but the amount of daily alcohol consumption is often an important factor for hypertension incidence [14]. Publication of data on combination of frequency of alcohol drinking and average alcohol consumption per day is warranted for the specific health checkups data. Lastly, there are multiple types of methods for deriving area-level deprivation level, and we used one of those methods. Confirming disparity using multiple kinds of area-level deprivation levels might be needed for verifying the robustness of these results.

\section{Abbreviations}

$\mathrm{Cl}$ : Confidence interval; SII: Slope index of inequality; RII: Relative index of inequality; BMI: Body mass index; BP: Blood pressure.

\section{Supplementary Information}

The online version contains supplementary material available at https://doi. org/10.1186/s13104-022-05931-6.

Additional file 1: Table S1. Basic characteristic of variables used in this study for the 335 secondary medical areas. Table S2. Number of participants for each type of measurement by deprivation level. Table S3. Sex and age group-specific proportion of each of the outcomes in all of Japan.

\section{Acknowledgements}

Enago has proofread the manuscript

\section{Authors' contributions}

Conceptualization: TO, JP. Data curation: TO. Formal analysis: TO. Methodology: TO. Funding acquisition: JP. Writing- original draft: TO. Writing — review \& editing: TO, JP.

Funding

This research was supported by the JSPS KAKENHI Grant Number 21K17231.

\section{Availability of data and materials}

The specific health checkups data were available from: https://www.mhlw. go.jp/stf/seisakunitsuite/bunya/0000177221_00010.html. The Census data other than data on the proportion of households living in rental housing are available from: https://www.e-stat.go.jp/regional-statistics/ssdsview. Data on the proportion of households living in rental housing were obtained from: https://www.e-stat.go.jp/stat-search/files?page $=1 \&$ toukei $=00200521 \&$ result page $=1$.

Map data by the secondary medical areas in Japan were obtained from the digital national land information of the Ministry of Land, Infrastructure, Transport and Tourism, and were available from: https://nlftp.mlit.go.jp/ksj/ $\mathrm{gml} /$ datalist/KsjTmplt-A38-v2_0.html. We generated Fig. 1 by processing the map data, and the following R packages were used: sf (http://cran.nexr.com/ web/packages/sf/sf.pdf), ggplot2 (https://cran.r-project.org/web/packages/ ggplot2/ggplot2.pdf), RColorBrewer (https://cran.r-project.org/web/packa 
ges/RColorBrewer/RColorBrewer.pdf), and ggthemes (https://cran.r-project. org/web/packages/ggthemes/ggthemes.pdf).

\section{Declarations}

\section{Ethics approval and consent to participate}

An ethical approval by institutional review board was not required for this study because government statistics data that are publicly available were used. All of the methods and analyses were conducted according to relevant guidelines.

\section{Consent for publication \\ Not applicable.}

\section{Competing interests}

None.

\section{Author details}

${ }^{1}$ Medical Information Center, Kyushu University Hospital, Maidashi3-1-1 Higashi-ku, Fukuoka, Fukuoka 812-8582, Japan. ${ }^{2}$ Department of Pharmaceutical Sciences, International University of Health and Welfare, Fukuoka, Japan.

Received: 27 September 2021 Accepted: 28 January 2022

Published online: 10 February 2022

\section{References}

1. Ikeda N, Inoue M, Iso H, Ikeda S, Satoh T, Noda M, et al. Adult mortality attributable to preventable risk factors for non-communicable diseases and injuries in Japan: a comparative risk assessment. PLoS Med. 2012;9:e1001160.

2. Ministry of Health, Labour and Welfare of Japan. The national health and nutrition survey report. https://www.mhlw.go.jp/bunya/kenkou/kenkou_ eiyou chousa.html. Accessed 19 Sep 2021.

3. Oka M, Yamamoto M, Mure K, Takeshita T, Arita M. Relationships between lifestyle, living environments, and incidence of hypertension in Japan (in Men): based on participant's data from the nationwide medical checkup. PLOS ONE. 2016;11(10):e0165313.

4. Kato K, Ohsawa M, Oguri S, Matsumura Y, Yanagawa H, Okayama A. The MAP of blood pressure in Japan. JJCDP. 2204;39(2): 120-126. Japanese

5. Fan AZ, Strasser SM, Zhang X, Fang J, Crawford CG. State socioeconomic indicators and self-reported hypertension among US adults, 2011 behavioral risk factor surveillance system. Prev Chronic Dis. 2015;26(12):E27.

6. Kauhl B, Maier W, Schweikart J, Keste A, Moskwyn M. Exploring the small-scale spatial distribution of hypertension and its association to area deprivation based on health insurance claims in Northeastern Germany. BMC Public Health. 2018;18(1):121.

7. Honjo K, Iso H, Nakaya T, Hanibuchi T, Ikeda A, Inoue M, Sawada N, Tsugane S, Japan Public Health Center-based Prospective Study Group. Impact of neighborhood socioeconomic conditions on the risk of stroke in Japan. J Epidemiol. 2015;25(3):254-60

8. Nakaya T, Honjo K, Hanibuchi T, Ikeda A, Iso H, Inoue M, Sawada N, Tsugane S, Japan Public Health Center-based Prospective Study Group. Associations of all-cause mortality with census-based neighbourhood deprivation and population density in Japan: a multilevel survival analysis. PLOS ONE. 2014;9(6):e97802.

9. Hanibuchi T, Nakaya T. Associations of neighborhood socioeconomic conditions with self-rated health, mental distress, and health behaviors: a nationwide cross-sectional study in Japan. Prev Med Rep. 2020;18:101075.

10. Kurotani K, Honjo K, Nakaya T, Ikeda A, Mizoue T, Sawada N, Tsugane S, Japan Public Health Center-based Prospective Study Group. Diet quality affects the association between census-based neighborhood deprivation and all-cause mortality in japanese men and women: The Japan Public Health Center-Based Prospective Study. Nutrients. 2019;11(9):2194.

11. Dochi M, Sakata K, Oishi M, Tanaka K, Kobayashi E, Suwazono Y. Smoking as an independent risk factor for hypertension: a 14-year longitudinal study in male Japanese workers. Tohoku J Exp Med. 2009;217(1):37-43.

12. Miyaki K, Song Y, Taneichi S, Tsutsumi A, Hashimoto H, Kawakami N, Takahashi M, Shimazu A, Inoue A, Kurioka S, Shimbo T. Socioeconomic status is significantly associated with dietary salt intakes and blood pressure in Japanese workers (J-HOPE Study). Int J Environ Res Public Health. 2013;10(3):980-93.

13. Nakanishi N, Makino K, Nishina K, Suzuki K, Tatara K. Relationship of light to moderate alcohol consumption and risk of hypertension in Japanese male office workers. Alcohol Clin Exp Res. 2002;26(7):988-94.

14. Nakamura K, Okamura T, Hayakawa T, Hozawa A, Kadowaki T, Murakami Y, Kita Y, Okayama A, Ueshima H, NIPPON DATA90 Research Group. The proportion of individuals with alcohol-induced hypertension among total hypertensives in a general Japanese population: NIPPON DATA90. Hypertens Res. 2007;30(8):663-8.

15. Hattori T, Konno S, Munakata M. Alcohol consumption and the risk of incident hypertension in the general population: the Watari Study. Jpn J Occup Med Traumatol. 2018;66(1):51-6 (Japanese).

16. Nagai M, Ohkubo T, Murakami Y, Takashima N, Kadota A, Miyagawa N, Saito Y, Nishi N, Okuda N, Kiyohara Y, Nakagawa H, Nakamura Y, Fujiyoshi A, Abbott RD, Okamura T, Okayama A, Ueshima H, Miura K, NIPPON DATA80/90/2010 Research Group. Secular trends of the impact of overweight and obesity on hypertension in Japan, 1980-2010. Hypertens Res. 2015:38(11):790-5.

17. Ministry of Health, Labor and Welfare. The specific health checkups and specific health guidance. https://www.mhlw.go.jp/stf/seisakunitsuite/ bunya/0000161103.html. Accessed 19 Sep 2020.

18. Tsushita K, Hosler AS, Miura K, Ito Y, Fukuda T, Kitamura A, Tatara K. Rationale and descriptive analysis of specific health guidance: the nationwide lifestyle intervention program targeting metabolic syndrome in Japan. J Atheroscler Thromb. 2018;25(4):308-22.

19. Ministry of Health, Labour and Welfare of Japan. 6th NDB Open. https:// www.mhlw.go.jp/stf/seisakunitsuite/bunya/0000177182.html. Accessed 19 Sep 2021.

20. Takahashi K, Tachimori H, Kan C, Nishi D, Okumura Y, Kato N, Takeshima T. Spatial analysis for regional behavior of patients with mental disorders in Japan. Psychiatry Clin Neurosci. 2017;71(4):254-61.

21. Ministry of Land, Infrastructure, Transport and Tourism. The digital national land information (Medical are data). https://nlftp.mlit.go.jp/ksj/ gml/datalist/KsjTmplt-A38-v2_0.html. Accessed 18 Sep 2021.

22. Umemura S, Arima H, Arima S, Asayama K, Dohi Y, Hirooka Y, Horio T, Hoshide S, Ikeda S, Ishimitsu T, Ito M, Ito S, Iwashima Y, Kai H, Kamide K, Kanno Y, Kashihara N, Kawano Y, Kikuchi T, Kitamura K, Kitazono T, Kohara K, Kudo M, Kumagai H, Matsumura K, Matsuura H, Miura K, Mukoyama M, Nakamura S, Ohkubo T, Ohya Y, Okura T, Rakugi H, Saitoh S, Shibata H, Shimosawa T, Suzuki H, Takahashi S, Tamura K, Tomiyama H, Tsuchihashi T, Ueda S, Uehara Y, Urata H, Hirawa N. The Japanese society of hypertension guidelines for the management of hypertension (JSH 2019). Hypertens Res. 2019;42(9):1235-481.

23. WHO Consultation on Obesity (1999: Geneva, Switzerland) \& World Health Organization. 2000. Obesity: preventing and managing the global epidemic : report of a WHO consultation. World Health Organization. https://apps.who.int/iris/handle/10665/42330

24. World Health Organization. Regional Office for the Western Pacific. 2000. The Asia-Pacific perspective : redefining obesity and its treatment. Sydney : Health Communications Australia. https://apps.who.int/iris/handle/ 10665/206936

25. Miyazaki S. Himansyou shinryou guideline 2016. Nippon Naika Gakkai Zasshi. 2018;107:262-8. https://doi.org/10.2169/naika.107.262.

26. Ministry of Internal Affairs and Communications. The census. https:// www.e-stat.go.jp/stat-search/files?page $=1 \&$ toukei $=00200521$. Accessed 19 Sep 2021

27. Ministry of Internal Affairs and Communications. State of prefectures and municipalities (System of social and demographic statistics). https:// www.e-stat.go.jp/regional-statistics/ssdsview. Accessed 19 Sep 2021.

28. McCartney G, Popham F, Katikireddi SV, Walsh D, Schofield L. How do trends in mortality inequalities by deprivation and education in Scotland and England \& Wales compare? A repeat cross-sectional study. BM Open. 2017;7(7):e017590.

29. Andrade FB, Antunes JLF, Souza Junior PRB, Lima-Costa MF, Oliveira C. Life course socioeconomic inequalities and oral health status in later life: ELSI-Brazil. Rev Saude Publica. 2018;52(Suppl 2):7s.

30. Renard F, Devleesschauwer B, Speybroeck N, Deboosere P. Monitoring health inequalities when the socio-economic composition changes: 
are the slope and relative indices of inequality appropriate? Results of a simulation study. BMC Public Health. 2019;19(1):662.

31. Shimozaki A, Imaki M, Yoshida Y, Kitakouji M, Tanada S. Ecologic study on obesity and social, economic and cultural factors at prefectural levels. J Urban Living Health Assoc. 2007;51(3):172-7.

32. Hasegawa T. Obesity proportion by prefecture and socioeconomic disparities. J Health Welfare Stat. 2011;58(3):18-22 (Japanese).

33. Hu MD, Lawrence KG, Bodkin MR, Kwok RK, Engel LS, Sandler DP. Neighborhood deprivation, obesity, and diabetes in residents of the US Gulf Coast. Am J Epidemiol. 2021;190(2):295-304.

34. Twaits A, Alwan NA. The association between area-based deprivation and change in body-mass index over time in primary school children: a population-based cohort study in Hampshire, UK. Int J Obes (Lond). 2020;44(3):628-36.

35. Grundmann N, Mielck A, Siegel M, Maier W. Area deprivation and the prevalence of type 2 diabetes and obesity: analysis at the municipality level in Germany. BMC Public Health. 2014;13(14):1264.

36. Babey SH, Hastert TA, Brown ER. Teens living in disadvantaged neighborhoods lack access to parks and get less physical activity. Policy Brief UCLA Cent Health Policy Res. 2007;(PB2007-4):1-6.

37. Morland KB, Evenson KR. Obesity prevalence and the local food environment. Health Place. 2009;15(2):491-5.

38. Fukuda Y, Nakamura K, Takano T. Accumulation of health risk behaviours is associated with lower socioeconomic status and women's urban residence: a multilevel analysis in Japan. BMC Public Health. 2005;27(5):53.

39. Nakamura S, Inayama T, Hata K, Matsushita M, Takahashi M, Harada K, Arao T. Association of household income and education with eating behaviors in Japanese adults: a cross-sectional study. BMC Public Health. 2016;22(16):61.

40. Reyes Matos U, Mesenburg MA, Victora CG. Socioeconomic inequalities in the prevalence of underweight, overweight, and obesity among women aged 20-49 in low- and middle-income countries. Int J Obes (Lond). 2020:44(3):609-16.

41. Tamura T, Kadomatsu Y, Tsukamoto M, Okada R, Sasakabe T, Kawai S, Hishida A, Hara M, Tanaka K, Shimoshikiryo I, Takezaki T, Watanabe I, Matsui D, Nishiyama T, Suzuki S, Endoh K, Kuriki K, Kita Y, Katsuura-Kamano S, Arisawa K, Ikezaki H, Furusyo N, Koyanagi YN, Oze I, Nakamura Y, Mikami $H$, Naito M, Wakai K. Association of exposure level to passive smoking with hypertension among lifetime nonsmokers in Japan: a cross-sectional study. Medicine (Baltimore). 2018;97(48):e13241.

42. Ueshima H. Explanation for the Japanese paradox: prevention of increase in coronary heart disease and reduction in stroke. J Atheroscler Thromb. 2007;14:278-86.

43. Tanaka H, Mackenbach JP, Kobayashi Y. Widening socioeconomic inequalities in smoking in Japan, 2001-2016. J Epidemiol. 2021;31 (6):369-77.

44. Tomioka K, Kurumatani N, Saeki K. The association between education and smoking prevalence, independent of occupation: a nationally representative survey in Japan. J Epidemiol. 2020;30(3):136-42.

45. Piontek D, Kraus L, Müller S, Pabst A. To what extent do age, period, and cohort patterns account for time trends and social inequalities in smoking? Sucht. 2010;56:361-71.

46. Okui T. An analysis of predictors for heavy alcohol drinking using nationally representative survey data in Japan. BMC Public Health. 2021;21(1):359.

47. Murakami $\mathrm{K}$, Hashimoto $\mathrm{H}$. Associations of education and income with heavy drinking and problem drinking among men: evidence from a population-based study in Japan. BMC Public Health. 2019;19(1):420.

48. Vinther-Larsen M, Huckle T, You R, Casswell S. Area level deprivation and drinking patterns among adolescents. Health Place. 2013;19:53-8.

49. Silveira CM, Siu ER, Anthony JC, Saito LP, de Andrade AG, Kutschenko A, Viana MC, Wang YP, Martins SS, Andrade LH. Drinking patterns and alcohol use disorders in São Paulo, Brazil: the role of neighborhood social deprivation and socioeconomic status. PLoS ONE. 2014;9(10):e108355.

50. Pollack CE, Cubbin C, Ahn D, Winkleby M. Neighbourhood deprivation and alcohol consumption: does the availability of alcohol play a role? Int J Epidemiol. 2005;34(4):772-80.

51. Fone DL, Farewell DM, White J, Lyons RA, Dunstan FD. Socioeconomic patterning of excess alcohol consumption and binge drinking: a crosssectional study of multilevel associations with neighbourhood deprivation. BMJ Open. 2013;3(4):e002337.
52. Fujita M, Sato Y, Nagashima K, Takahashi S, Hata A. Income related inequality of health care access in Japan: a retrospective cohort study. PLOS ONE. 2016;11(3):e0151690.

53. Miura K, Okuda N, Turin TC, Takashima N, Nakagawa H, Nakamura K, Yoshita K, Okayama A, Ueshima H, NIPPON DATA80/90 Research Group. Dietary salt intake and blood pressure in a representative Japanese population: baseline analyses of NIPPON DATA80. J Epidemiol. 2010;20(Suppl 3):S524-30

54. Miyagawa N, Okuda N, Nakagawa H, Takezaki T, Nishi N, Takashima N, Fujiyoshi A, Ohkubo T, Kadota A, Okamura T, Ueshima H, Okayama A, Miura K. Socioeconomic status associated with urinary sodium and potassium excretion in Japan: NIPPON DATA2010. J Epidemiol. 2018;28(Suppl 3):S29-34.

\section{Publisher's Note}

Springer Nature remains neutral with regard to jurisdictional claims in published maps and institutional affiliations.
Ready to submit your research? Choose BMC and benefit from:

- fast, convenient online submission

- thorough peer review by experienced researchers in your field

- rapid publication on acceptance

- support for research data, including large and complex data types

- gold Open Access which fosters wider collaboration and increased citations

- maximum visibility for your research: over 100M website views per year

At BMC, research is always in progress.

Learn more biomedcentral.com/submissions 